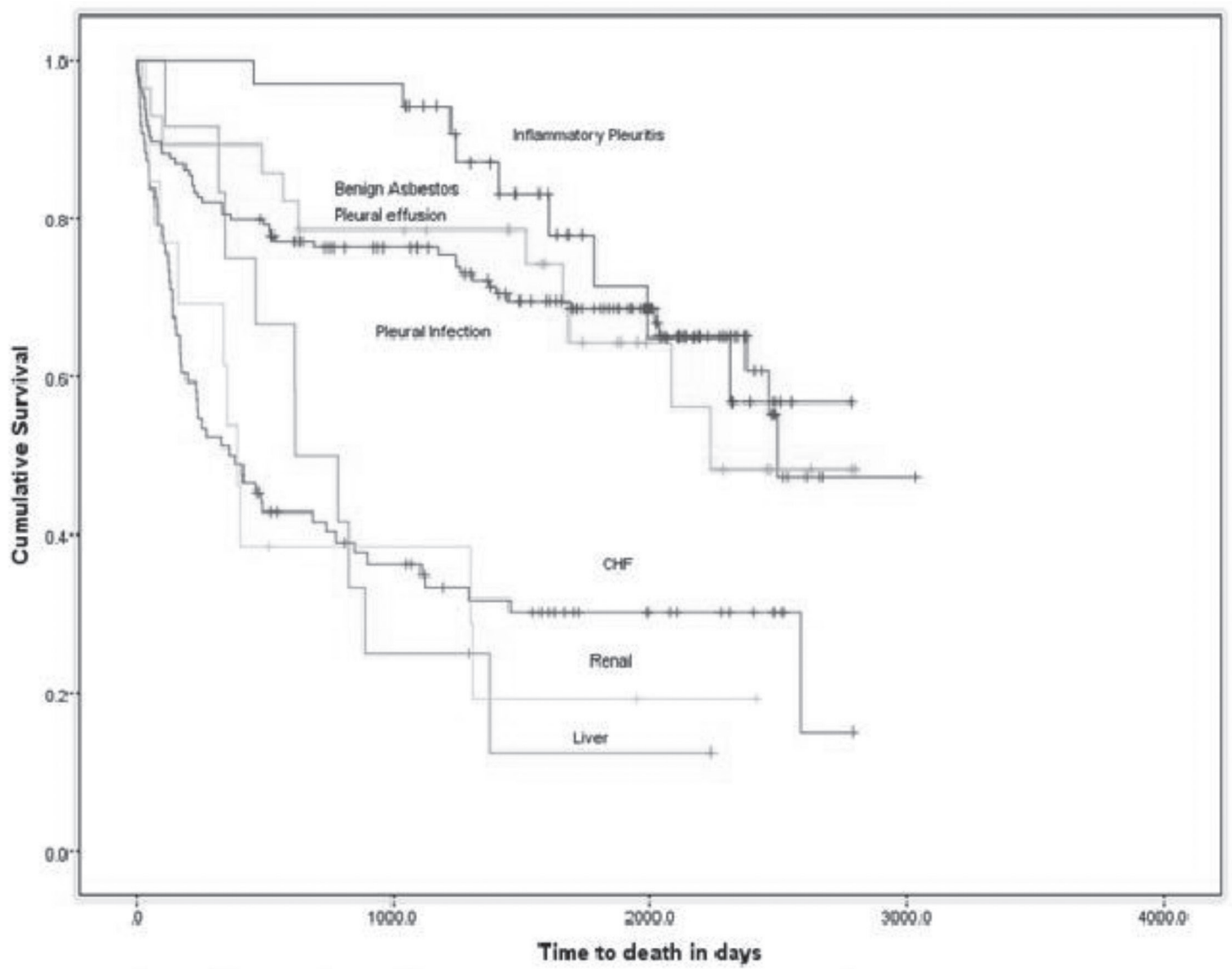

Abstract S92 Figure 1 Kaplan-meier survival curve according to disease type

\section{S93 NOVEL BIOMARKERS IN PROGNOSTICATION AND TREATMENT MONITORING OF MALIGNANT PLEURAL MESOTHELIOMA- A SYSTEMATIC REVIEW}

${ }^{1}$ DT Arnold, ${ }^{1} \mathrm{D}$ De Fonseka, ${ }^{2} \mathrm{FW}$ Hamilton, ${ }^{1} \mathrm{NA}$ Maskell. ${ }^{1}$ Academic Respiratory Unit Bristol, UK; ${ }^{2}$ Southmead Hospital, Bristol, UK

\subsection{6/thoraxjnl-2016-209333.99}

Introduction Pemetrexed with cisplatin is the only UK licensed treatment for malignant pleural mesothelioma (MPM) following an RCT that demonstrated a survival advantage of 2-3 months and response rate of 30-40\% (Vogelzang, 2003). Radiological markers of treatment response and prognostication have significant limitations due to the morphology of the disease. Therefore, serum or pleural fluid biomarkers that could act as an adjunct to radiological assessment would be of significant value. The aim of this systematic review was to collate and summarise the literature relating to this topic.

Methods The PubMed and EMBASE databases were interrogated using pre-defined search strings (with English language restrictions) up to 30 June 2016, with no early date limit applied. Two independent researchers (DA and $\mathrm{FH}$ ) read the abstracts and, using the Quality in Prognostic Studies (QUIPS) tool, selected the studies to be included in the final review.

Results From the 795 abstracts generated by the search strategy, 41 relevant studies were identified. Serum mesothelin was the most studied biomarker with 20 studies assessing its role in prognostication. A high serum mesothelin at baseline was thought to be an independent marker of poor prognosis in epithelioid MPM, however, recent studies suggest this is because levels increase with tumour stage and bulk. Six studies assessed serial serum mesothelin measurements during chemotherapy and all showed that it can be a proxy for treatment response and prognosis (see table). Pleural fluid mesothelin was not a useful prognostic biomarker in the 4 relevant studies. Serum Osetopontin (OPN) was the topic of 5 studies and appeared to offer prognostic information at baseline even after adjustment for covariates. Other serum or pleural fluid biomarkers such as fibulin-3, megakaryocyte-potentiating factor, hyaluronic acid and VEGF have shown prognostic utility in individual papers but are yet to be reproduced in large cohort studies.

Discussion The literature suggests that a falling serum mesothelin following chemotherapy correlates with treatment response and improved overall survival. This could be of significant value to clinicians in deciding ongoing treatment, but a larger prospective study is required before its inclusion in routine clinical practice.

\section{S94 BIOLOGICAL MARKERS OF FAVOURABLE PROGNOSIS AND SUCCESSFUL PLEURODESIS FOR MALIGNANT PLEURAL EFFUSION}

${ }^{1}$ I Psallidas, ${ }^{1} \mathrm{~N}$ Kanellakis, ${ }^{2} \mathrm{ML}$ Thezenas, ${ }^{2} \mathrm{P}$ Charles, ${ }^{3} \mathrm{JP}$ Corcoran, ${ }^{3} \mathrm{R}$ Hallifax, ${ }^{3} \mathrm{~A}$ Talwar, ${ }^{1} \mathrm{CC}$ Pascuall, ${ }^{2} \mathrm{~B}$ Kessler, ${ }^{1} \mathrm{NM}$ Rahman. 'Laboratory of Pleural Translational Research, Nuffield Department of Medicine, University of Oxford, Oxford, UKi ${ }^{2} T D I$ Mass Spectrometry Laboratory, University of Oxford, Oxford, UK; ${ }^{3}$ Oxford Centre for Respiratory Medicine, Oxford, UK

10.1136/thoraxjnl-2016-209333.100 
Abstract S93 Table 1 Studies assessing treatment response or survival using serial serum mesothelins during treatment

\begin{tabular}{|c|c|c|c|}
\hline $\begin{array}{l}\text { Author } \\
\text { (year) }\end{array}$ & $\begin{array}{l}\text { Treatment } \\
\text { (no. of patients) }\end{array}$ & Outcome measure & Results \\
\hline \multirow[t]{2}{*}{ Hooper (2015) } & P/C- 58 & Mod RECIST CT & $\begin{array}{l}\text { Falling serum mesothelin following chemotherapy associated with longer time } \\
\text { to progression }(\mathrm{p}<0.001) \text { and } \mathrm{OS}(\mathrm{p}=0.031) \text {. }\end{array}$ \\
\hline & BSC- 15 & OS & \\
\hline $\begin{array}{l}\text { Hassan } \\
\text { (2014) }\end{array}$ & $\begin{array}{l}\mathrm{P} / \mathrm{C} \& \text { immuno- } \\
\text { toxin- } 20\end{array}$ & Mod RECIST CT & $\begin{array}{l}\text { Fall in serum mesothelin correlated with radiological response with } 70 \% \\
\text { accuracy }(p=0.003) \text {. }\end{array}$ \\
\hline Franko & G/C- 56, P/C- 9 & Mod RECIST CT & $\begin{array}{l}\text { Significantly lower mean serum mesothelin in partial response or stable } \\
\text { disease compared to progressive disease }(\mathrm{p}=0.001) \text {. }\end{array}$ \\
\hline (2012) & EPP- 1, BSC- 4 & & \\
\hline \multirow[t]{2}{*}{$\begin{array}{l}\text { Hollevoet } \\
(2011)\end{array}$} & P/C- 57 & Mod RECIST CT & $\begin{array}{l}\text { Partial response to chemotherapy correlated with a } 34 \% \text { fall in mesothelin } \\
(p=0.010) \text { compared to a } 54 \% \text { rise in progressive disease }(p<0.001) .\end{array}$ \\
\hline & EPP-5 & & \\
\hline \multirow[t]{2}{*}{$\begin{array}{l}\text { Creaney, } \\
\text { (2011) }\end{array}$} & $\begin{array}{l}\text { Chemo- } 61 \text {, Tri- } 8 \text {, } \\
\text { BSC- } 25\end{array}$ & Mod RECIST CT & $\begin{array}{l}\text { Falling mesothelin was associated with better OS ( } 19 \text { months) compared to } \\
\text { static ( } 13 \text { months) or rising levels ( } 15 \text { months). }(\mathrm{p}=0.001) .\end{array}$ \\
\hline & & OS & \\
\hline $\begin{array}{l}\text { Wheatley-Price } \\
(2010)\end{array}$ & $\begin{array}{l}\text { Chemo- 21, EPP-8, } \\
\text { BSC- } 13\end{array}$ & Mod RECIST CT & $\begin{array}{l}\text { Relative change in serum mesothelin from baseline }(>10 \%) \text { significantly asso- } \\
\text { ciated with disease progression }(p<0.001) \text {. }\end{array}$ \\
\hline
\end{tabular}

P- pemetrexed C- cisplatin G- gemcitabine, Chemo- chemotherapy (not specified), BSC- best supportive care, EPP- extra-pleural pneumonectomy, Tri- trimodality. Mod RECIST CT- Modified Response Evaluation Criteria In Solid Tumors CT, OS- Overall survival.

Introduction and objectives Malignant pleural effusion (MPE) is a rapidly rising healthcare burden and critically hampers the patients' survival and quality of life. Current treatments aim to symptoms' palliation and talc pleurodesis remains a standard therapeutic modality. There is relatively little high quality research data in prediction of patients' survival and successful pleurodesis. Therefore prognostic and therapeutic biomarkers are desperately needed.

Aim To identify and validate novel prognostic and therapeutic biomarkers in MPE.

Methods Clinical data and pleural fluids from MPE patients, prior to treatment have been prospectively collected for TIME2 trial. According to the trial database patients have been classified in two different groups: survival cohort (poor, $n=20 /$ good, $\mathrm{n}=14$ ) and treatment outcome cohort (success, $\mathrm{n}=15 /$ failure, $\mathrm{n}=11$ ). Pleural fluids on enrolment were assessed with mass spectrometry profiling after depletion of the 12 most abundant proteins. Full protein profile analysed with R software and ELISA technique was performed for the validation of the results. Pathway analysis on samples performed with Ingenuity Pathway Analysis software.

Results With the use of mass spectrometry we identified 1,154 proteins in the pleural fluid, 167 of which were statistical significant (two tailed T-Test, $\mathrm{p}<0.05$ ) between survival groups and 97 of which were statistically significant (two tailed T-Test, $\mathrm{p}<0.05$ ) between the pleurodesis groups. Analysis of the data (cross validated by 3 independent core bioinformatic groups) identified 10 survival and 3 pleurodesis biomarkers that were differentially expressed in the favourable prognosis and treatment success group respectively. Exploration of the mass spectrometry data identified pathways that were upregulated on patients with favourable survival that could be used for targeted therapies.

Conclusions Based on unique database survival and therapeutic biomarkers were identified that can potentially stratify patients' management. The results are currently validated on a different retrospective dataset (TIME1 trial) and with a prospective clinical trial (SIMPLE study).

\section{S95 AMBULATORY MANAGEMENT OF PNEUMOTHORAX: IS THERE A NEED FOR A DEDICATED PLEURAL TEAM-LED SERVICE?}

A Fawzi, N Maddekar, S Khan, S Bikmalla, W Osman, U Maqsood, M Haris. Royal Stoke University Hospital, Stoke-on-Trent, UK

\subsection{6/thoraxjnl-2016-209333.101}

Introduction Small, asymptomatic pneumothoraces may be managed as outpatients. Several studies show that small-bore catheters and Heimlich valves may be used in the treatment of pneumothoraces. A systematic review of the literature ${ }^{1}$ showed successful outpatient management of pneumothorax. Despite good evidence to support ambulatory approach, there has been slow development of this service across the UK. We wished to assess the number of potential primary spontaneous pneumothorax patients that could be managed as outpatients in a large teaching hospital.

Methods Hospital attendances of pneumothorax at a large teaching hospital between 2012-2015 were reviewed. Type of 